\title{
La conquista misógina en la memoria posfranquista: Los girasoles ciegos de Alberto Méndez.
}

\author{
Lisa DiGiovanni \\ Keene State College \\ Idigiovanni@keene.edu
}

\begin{abstract}
More than eight decades after its eruption, the Spanish Civil War (19361939 ) is still a point of division in Spanish society. Since the mid-1990s, new memorial accounts and novels have emerged that have explored the multiple types of violence during the dictatorship from the perspective of those who had been silenced. In this essay, I emphasize the role of misogynist discourses in postwar political repression and explore their literary representation in the novel Los girasoles ciegos (2004) by Alberto Méndez (Madrid, 1941-2004). The text constitutes an imaginative response that, by moving beyond a critique of violence, helps up to decipher the ways in which the Franco regime's supporters constructed a version of history to relentlessly defend patriarchal, nationalist, Catholic and colonial values. With its multiple narrators, thematic complexity
\end{abstract}


and fragmentary organization, the author denaturalizes the regime's underlying interdependent ideologies and deepens our understanding of their crucial role in the repression of republican women. The text invites us to imagine how gendered acts of domination contributed to the broader political goal of internal colonization, which meant the restoration of the hegemony of the military, the Catholic Church and the economic elites in postwar Spain. Through narrative strategies characteristic of literature, Méndez confronts the ways in which the Spanish Civil War has been glorified through social constructions of aggressive masculinity and, by extension, he renders visible the link between violence, gender and discourse.

Keywords: Spanish Civil War; Franco Dictatorship; Memory; Literature; Gender; Misogyny; Masculinity; Authoritarianism; Fascism; Contemporary Spanish Culture

\section{Resumen}

Más de ocho décadas después de su estallido, la Guerra Civil española (19361939) es aún un punto de escisión entre los españoles. Desde mediados de los años noventa se observa una oleada de memorias y novelas que han explorado los múltiples tipos de violencia durante la dictadura desde la perspectiva de los que habían sido silenciados. En este ensayo, enfatizo el rol de los discursos misóginos en la represión política de la posguerra y exploro su representación literaria en la novela Los girasoles ciegos (2004) de Alberto Méndez (Madrid, 1941-2004). El texto es una respuesta imaginativa que, al ir más allá de la crítica de la violencia, ayuda a descifrar la manera en que los partidarios franquistas construyeron una versión sesgada de la historia para defender implacablemente los valores patriarcales, nacionalistas, católicos y coloniales. Con sus múltiples narradores, complejidad temática y organización fragmentaria el autor desnaturaliza las creencias misóginas del régimen y profundiza nuestra comprensión de su papel en la represión de las mujeres republicanas. El texto nos invita a imaginar cómo tal acto de dominación contribuyó a la meta política más amplia de colonización interna, que significó la restauración de la hegemonía de los militares, la Iglesia Católica y las élites 
económicas en la España de la posguerra. A través de las estrategias narrativas propias de la literatura, Méndez interroga las formas en las cuales la Guerra Civil española ha sido glorificada a través de ciertas construcciones de masculinidad agresiva y así hace visible el vínculo clave entre la violencia, el género y los discursos.

Palabras clave: Guerra Civil española; dictadura; franquismo; memoria; literatura; género; misoginia

$\mathbf{M}$ ás de ocho décadas después de su estallido, la Guerra Civil española (1936-1939) es aún un punto de escisión entre los españoles. Desde mediados de los años noventa se observa una oleada de memorias y libros de historia que han explorado los múltiples tipos de violencia durante la dictadura desde la perspectiva de los que habían sido silenciados. Sebastian Balfour, uno de los historiadores más innovadores que ha estudiado la contienda, publicó en el año 2002 una investigación que propone una relectura de la versión sesgada del régimen acerca de la guerra. Balfour enfatiza cómo el concepto imperialista de la superioridad religiosa formaba la ideología del nacionalismo católico y servía para justificar la represión social, política, y cultural. Nos recuerda que el Ejército de África dirigido por Franco invadió la península en 1936 con la misión de destruir al enemigo ateo y restablecer la "auténtica" España católica (Balfour X). ${ }^{2}$ Otros historiadores como Mary Vincent y Julián Casanova han situado así mismo el discurso franquista dentro de un marco escatológico señalando que, a través de una red de discursos e imágenes, los defensores de la dictadura se representaron a sí mismos como los poseedores de un mandato sagrado, proyectándose como los elegidos para llevar a cabo una cruzada. De modo semejante a los antiguos colonizadores españoles, los cruzados nacionalcatólicos españoles pretendían en pleno siglo XX defender el dominio imperial a través de la religión y los valores tradicionales de 
aquello que definían como la Hispanidad. La maquinaria política de Franco trató de legitimar el golpe de estado al establecer una unión entre la Iglesia y el régimen y una visión hegemónica de un Estado católico "limpio". Los partidarios de Franco usaron todo un léxico eufemístico como herramienta de conquista cultural y política.

Existen detractores de la versión franquista de la historia que reconocen que el discurso político-ideológico del régimen tenía dimensiones imperialistas y también patriarcales. Sin embargo, concuerdo con la historiadora Mary Nash en que nuestros conocimientos sobre las mujeres en la Guerra Civil y en la posguerra "siguen siendo fragmentarios y permanece la necesidad de revisar las perspectivas de género y avanzar en la investigación en este campo" (Nash, "Mujeres" 63). Muchos artefactos dan cuenta de cómo funcionaba el sistema social durante el franquismo. Los textos escolares de la posguerra resultan muy ilustrativos de cómo la figura de la mujer se convirtió en un locus para la articulación de los principios de la virtud católica y el nacionalismo. ${ }^{3}$ Un conjunto de instituciones, costumbres y leyes que prescribían la conducta femenina pasiva y piadosa fomentó una ideología social conservadora que trató de debilitar los intentos republicanos de desafiar los roles de género tradicionales. ${ }^{4}$ Los hombres eran representados como soldados y constructores de la nación, mientras que las mujeres eran definidas como esposas y madres. Este movimiento sociopolítico basado en la intolerancia religiosa y el chauvinismo agresivo fue particularmente desmoralizante para las mujeres de izquierdas que veían en la Segunda República un camino hacia la igualdad de género y de clase. Como mantiene la historiadora Helen Graham con respecto a las consecuencias políticas y económicas del franquismo, los aspectos de la identidad como la religión, la afiliación política, la clase, el género y la identidad sexual, definieron la experiencia particular de las mujeres durante la posguerra: “El género no puede significar una sola experiencia, porque siempre se divide en la clase socioeconómica y otras identidades culturales y 
políticas" ("Gender" 183). ${ }^{5}$

Es de suma importancia entender la relación entre estas identidades y discursos y preguntar ¿qué tan central era la cuestión de género en la maquinaria dictatorial y qué rol tenía la misoginia en los actos violentos de la venganza política de la posguerra? Numerosos académicos han teorizado el papel de la literatura en las políticas de la memoria y han tratado de esclarecer cómo las atrocidades franquistas se ven representadas a través de la ficción. En particular, el tema de la misoginia en el contexto franquista y su interpretación literaria deben ser analizados con más profundidad. ¿Cómo retratar el vínculo entre la construcción social de la masculinidad y la justificación de la violencia? ¿Cómo escribir sobre la convergencia de discursos que crearon un conjunto de retos particularmente adversos para las mujeres republicanas? Se puede ubicar la novela Los girasoles ciegos (2004) de Alberto Méndez (Madrid, 1941-2004) dentro de esta formulación, la de usar textos literarios tanto para estudiar la representación de la posguerra como las relaciones de género. El texto es una respuesta imaginativa que, al ir más allá de la crítica de la violencia, ayuda a descifrar la manera en que los partidarios franquistas construyeron una versión sesgada de la historia para defender implacablemente los valores patriarcales, nacionalistas, católicos y coloniales. Con sus múltiples narradores, complejidad temática, organización fragmentaria, el autor desnaturaliza las subyacentes creencias misóginas y profundiza nuestra comprensión de la memoria traumática enraizada en la represión dictatorial que tuvo a la vez especificidades de género.

Para un entendimiento cabal, se debe interpretar Los girasoles ciegos en el contexto de su producción, es decir, durante la primera década del siglo XXI cuando la memoria de la Guerra Civil volvió a emerger de manera patente en la imaginación literaria. La urgencia de tratar el tema de la memoria surgió de varios factores, entre ellos la preocupación por el legado de la dictadura, las demandas de saldar cuentas con el pasado y la muerte inminente de 
los perpetradores y las víctimas de la violencia dictatorial. Dentro de dicho panorama, Méndez publicó Los girasoles ciegos después de haberse dedicado al mundo de la edición y la militancia política en contra de la dictadura. Al fallecer en 2004, el año de la publicación de su novela, no llegó a ver su aceptación entre la crítica y el público. Según su familia "Los dos últimos años antes de publicar Los girasoles ciegos se dedicó a comprar libros de viejo escritos por los vencedores de la Guerra Civil, obras a las que no se había acercado nunca y consideraba interesantes para documentarse, y a escribir miles de cuartillas que luego fue puliendo y puliendo hasta finalizar su trabajo" (Intxausti). Efectivamente son las voces de los partidarios franquistas que Méndez convoca para subvertirlas y desnaturalizarlas y así generar una nueva forma de entender el pasado.

Se trata de una novela híbrida que abarca cuatro historias interconectadas de "derrotas" que tienen lugar en diversos ámbitos entre 1936 y 1942. Como indica Antonio Gómez López-Quiñones, los relatos "no solo comparten motivos y temas comunes, sino también personajes e hilos narrativos" (103). No obstante, me centro en la última historia que puede ser leída de manera independiente. Titulada "La cuarta derrota: 1942 o Los girasoles ciegos" esta sección fue adaptada al cine en 2008 por José Luis Cuerda. ${ }^{6}$ Esta narración presta especial atención a la alianza entre la Iglesia y el régimen y su complicidad en la persecución de las voces republicanas.? Al mismo tiempo, Méndez llama la atención respecto a las formas en las que el régimen de Franco trató de controlar el comportamiento de las mujeres y cómo en este contexto el género, la clase y la religión determinaron la obtención o la pérdida de estatus y poder. Mediante el análisis de ciertas representaciones de personajes, sugiero que el texto pone de relieve las formas en que los discursos del régimen franquista crearon un sistema interseccional de opresión que legitimó actos de violencia, como la tortura física y psicológica. La interseccionalidad, una teoría sociológica y feminista desarrollada por Kimberle Crenshaw, sostiene que varias categorías 
de prejuicio socialmente construidas están íntimamente relacionadas entre sí y forman parte de un complejo sistema de discriminación social y económica. La novela Los girasoles ciegos nos pide considerar cómo las formas de injusticia en la sociedad franquista no funcionaron de manera aislada, sino más bien en conjunto, creando de manera interseccional lo que la socióloga feminista Patricia Hill Collins Ilama una "matriz de dominación."8

El concepto de la interseccionalidad es clave, pero este análisis va más allá del trabajo inicial que identifica las intersecciones de la identidad. Destaco cómo la novela relata los efectos de una ideología construida por discursos imperialistas y sexistas interdependientes. Méndez interroga las formas en que se utilizaron los discursos para controlar a las mujeres republicanas y sus cuerpos. El texto sugiere que tal acto de dominación contribuyó a la meta política más amplia de colonización interna, que significó la restauración de la hegemonía de los militares, la Iglesia Católica y las élites económicas en la España de la posguerra. Al marcar las relaciones de privilegio y de dominación, el presente ensayo profundiza las discusiones sobre la interseccionalidad. Méndez retrata tanto las identidades privilegiadas dentro del discurso colonialista como las marginalizadas. El entramado esquemático representa el poder desde la perspectiva del colonizador franquista y también del colonizado republicano. El efecto es notable; nos pide que consideremos cómo las categorías de identidad están definidas por los discursos del ambiente sociopolítico. El texto desnaturaliza el discurso franquista según el cual la familia simbolizaba las relaciones "naturales" de poder (el padre sobre el hijo, el hombre sobre la mujer). Sugiere que esas relaciones de poder determinaban a la vez la lógica de otras (los nacionales "vencedores" sobre los republicanos "vencidos") que se definieron a través de un lenguaje paternalista. ${ }^{9}$ El texto también pavimenta el camino para que los lectores cuestionen la posibilidad de desamarrar la memoria de los ideales políticos y éticos de los sujetos que recuerdan. Para fortalecer los argumentos que he planteado, utilizo, más 
adelante, las propuestas teóricas de Elizabeth Jelin, Anne Mcclintock, Ania Loomba, y Rita Laura Segato.

La narración de Los girasoles ciegos se sitúa en Madrid en 1942, y gira en torno a una familia de cuatro miembros: Elena, una costurera de clase obrera y madre de dos hijos; Elenita, su hija adolescente que se ha echado al monte con su compañero, un joven poeta comunista; Lorenzo, el hijo menor de Elena; y, finalmente, su marido, Ricardo, un intelectual republicano obligado a vivir como "topo" en un armario por temor a represalias por sus compromisos políticos durante la guerra. Para mantener la apariencia de que Ricardo murió en la guerra, Lorenzo y Elena viven aislados del resto de la sociedad, en constante temor. La familia se enfrenta a las privaciones económicas, la pérdida de seres queridos, los repetidos ataques de las escuadras falangistas y las humillaciones diarias provocadas por los vencedores. El antagonista de la historia es el Hermano Salvador, el maestro de Lorenzo, anteriormente soldado fascista libertino, y ahora diácono, que cree que Elena es viuda. Este personaje representa la represión emocional, psicológica, y sexual que busca en la Iglesia una reafirmación de su papel de triunfo en la guerra o cruzada y una vía para reprimir su deseo sexual. Sin embargo, este termina rechazando el celibato doctrinal y comienza a acosar a Elena. Disfraza su deseo por ella como una preocupación benévola por su bienestar basado en una noción patriarcal de la familia que considera a la madre y al niño como subordinados a la figura del padre autoritario. En la escena final culminante, decide deshacerse de su hábito para satisfacer sus deseos carnales y ejercer poder sobre ella. Cuando ella se opone a sus avances sexuales, él explota en un ataque de rabia e intenta violarla. Ricardo entonces emerge del armario para defenderla, momento en el cual Salvador huye para notificar a la policía. Sabiendo que no había opción real para la supervivencia, Ricardo se lanza desde la ventana del apartamento, y de esta forma Salvador termina destruyendo a la familia.

El análisis que presento a continuación se centrará especialmente en 
el comportamiento y las confesiones de Salvador. En ellos vemos creencias acerca de la naturalidad de la familia patriarcal, una división estricta de las esferas para las mujeres y los hombres, y la "verdadera naturaleza" de las mujeres como está ordenado por Dios. Este personaje da voz a un fanatismo religioso y bélico que supone una adhesión a la destrucción de identidades femeninas "negativas" como la "marimacho", la "roja” y la "atea”. Puesto que estas identidades ya estaban "corrompidas," cualquiera que tuviera más de una de estas identidades era subhumana y, por lo tanto, carecía de integridad corporal y de un reclamo legítimo de derechos humanos. A mi entender, Méndez lleva a cabo esta representación crítica a través de la creación de tres narradores diferentes: el Hermano Salvador, cuya narración adopta la forma de una confesión que busca justificar los acontecimientos que condujeron al encuentro violento final con Elena; Lorenzo, quien, ahora en la edad adulta, reflexiona sobre sus persistentes y traumáticos recuerdos de la infancia; $y$, finalmente, un narrador omnisciente en tercera persona que narra los acontecimientos a medida que ocurren.

La diversidad de las formas narrativas y corrientes temporales es significativa. La obsesión de Salvador por la "verdad" contrasta fuertemente con el monólogo interior y contemplativo de Lorenzo que cuestiona una serie de relaciones simbióticas entre el pasado y el presente, la realidad y la representación, y la historia y la memoria. El pasado para Lorenzo es difícil de alcanzar, accesible solo a través de los fragmentos de la memoria que están inevitablemente filtrados a través de una lente subjetiva. Además, su narrativa cataloga los efectos a largo plazo de la represión y la violencia de los años de la posguerra, y de esta manera subraya la presencia del pasado en el presente. Méndez yuxtapone estas lentes narrativas contrastadas con el fin de derribar las pretensiones de verdad del régimen franquista y señalar las distorsiones míticas a las que la historia había sido sometida durante el régimen. Como he sugerido, se aborda la política de género a lo largo de la novela; sin embargo, 
el lector no tiene acceso a las reflexiones de Elena y su perspectiva de las operaciones paternalistas del Estado y la iglesia franquistas. También está ausente la voz del padre de Lorenzo. Como sugiere el título, es uno de los girasoles ciegos, sumergidos en la oscuridad por las fuerzas del régimen. A través de estos silencios y alusiones a la oscuridad y la ceguera, la novela ilumina la exclusión sistemática de la oposición en la esfera pública y como consecuencia los obstáculos al florecimiento de la diversidad intelectual. Me centraré ahora específicamente en el personaje de Salvador, ya que representa la confluencia de los valores del régimen que facilitaron la subordinación y cierta colonización de las mujeres republicanas y sus cuerpos.

\section{Los mitos misóginos del patriarcado colonialista}

La historia comienza con una confesión en la que el personaje principal, Salvador, hace referencia a la iconografía católica para reivindicar su papel en la Guerra Civil como un cruzado:

Todo comenzó cuando, siguiendo su consejo, Padre, me alisté en el Glorioso Ejército Nacional. Combatí tres años en el frente participando en la Cruzada [...] Contribuí con mi sangre a transformar el monte Quemado en un monte Exterminio. (105)

Este mito grandioso celebra la guerra como una batalla santa y al soldado masculino como un liberador triunfante en la lucha contra la secularización del proletariado que había "invadido" la patria. Salvador establece un paralelo entre la crucifixión de Jesús en el Gólgota y la Guerra Civil, reivindicando con ello el levantamiento militar, y el derramamiento de sangre, como un acto necesario en la trayectoria de la redención de la nación. Aquí es significativo el carácter colonialista del lenguaje del diácono, con su énfasis en la salvación y la purificación moral de los infieles. Esa retórica se puede encontrar en innumerables discursos de la posguerra difundidos por el régimen, como por 
ejemplo aquél en el que Franco declaró: "No es un capricho el sufrimiento de una nación en un punto de su historia; es el castigo espiritual, castigo que Dios impone a una vida torcida, a una historia no limpia" (qtd. in Casanova, La iglesia 235). El lenguaje de Franco evoca conceptos coloniales que asociaban la virtud católica con la limpieza que, desde este punto de vista, simbolizó la superioridad moral de los colonizadores. ${ }^{10}$ Esta obsesión con la virtud de la identidad nacionalcatólica refleja la fijación con la conversión durante el período colonial. Como mantiene Jo Labanyi, esta preocupación era sobre todo la expresión de una intolerancia de la diferencia cultural ("Miscegenation" 58). De manera significativa, el discurso colonial español del siglo XVI legitimaba en gran medida el mestizaje como una forma de mejorar la raza. Sin embargo, como sostiene Labanyi, en realidad esta lógica normalizó la violación, es decir, el discurso colonial español transmitió el mito del hombre blanco que dona generosamente su semilla a la mujer de color, fundando de esta manera una nueva raza híbrida en la que las diferencias fueron trascendidas y redimidas ("Miscegenation" 58). En Los girasoles ciegos esta retórica colonial, que reivindica la redención de la mujer a través de la conquista y el sometimiento sexual, determina la perspectiva de Salvador y provoca su acosamiento a Elena. El desarrollo de ese personaje y su voz narrativa sirven para desterrar las dimensiones misóginas del discurso franquista y poner en cuestión el marco interpretativo del pasado que ha hecho invisible las consecuencias traumáticas del dicho discurso.

Antes de dar paso al análisis de las otras voces narrativas que obligan al lector a mediar entre diferentes realidades, es imprescindible profundizar más en el análisis de la retórica de Salvador y su énfasis en la necesidad de promover en la sociedad un entusiasmo patriarcal militante. Su léxico alude al escritor fascista Ernesto Giménez Caballero, cuya obra más famosa, Genio de España (1932), reúne los valores coloniales, católicos, fascistas, y patriarcales con la metáfora de la limpieza de la sangre del cordero, la ablución del pecado 
de la mujer, y la purga del salvajismo de los izquierdistas. El escritor falangista comparó el Madrid republicano con la ramera de Babilonia, que simboliza tanto el pecado sexual como el anticristo mencionado en el Libro de las Revelaciones o Apocalipsis (cit. en Labanyi Myth 36-37). Por el contrario, con su uso abiertamente sexista y dogmático de la lengua, comparó al fundador de la Falange, José Antonio Primo de Rivera, con el Cordero de Dios que expió los pecados de España. Según Giménez Caballero, los falangistas pudieron rescatar la nación del mal, como los conquistadores habían hecho anteriormente durante el siglo XVI, mediante la difusión de sus genes regeneradores." En LoS girasoles ciegos, Salvador trasmite las reflexiones escatológicas que formaban parte del discurso más amplio del régimen. Cuenta su historia en primera persona, continuamente reciclando los mitos bíblicos que definían a los hombres como los salvadores de la humanidad y a las mujeres como la fuente de su decadencia. Sin embargo, Salvador no es el poseedor de la narrativa. La yuxtaposición de perspectivas brinda abundantes oportunidades para el desenmascaramiento del autoengaño de los franquistas.

Es pertinente indagar el tipo de temporalidad que enfatizan los discursos del régimen que Salvador utiliza para guiar su comportamiento y justificar sus acciones. Una corriente visible en las reflexiones del diácono es la nostalgia por el pasado imperial en comparación con el estado degenerado de la humanidad en el presente. El pasado imperial se convierte así en sinónimo de la "Edad de Oro" y la modernidad en sinónimo de "la Caída". El lenguaje nostálgico del diácono insiste en la idea de que la historia republicana de España fue una divergencia no "auténtica" que se salió de sus orígenes naturales, y que el régimen salvó al país al dirigirlo de nuevo a sus raíces católicas esenciales. El aspirante a sacerdote se ve a sí mismo como un pastor cuyo mensaje defiende la purificación moral de los elementos pecadores introducidos por la República. Salvador, cuyo nombre es simbólico, se compara a sí mismo con Jacques-Bénigne Bossuet (1627-1704), el sacerdote de la corte de Luis XIV de 
Francia y el defensor del absolutismo político: "Me sentí pastor y fui feliz al saber que había descarriados en mi rebaño [...] Como Bossuet hice acopio de mi cáliz para darles de beber los secretos del Señor" (118). Bossuet fue un político influyente que argumentó que el gobierno era divino y que los reyes recibían su poder de Dios.

De forma semejante, el Hermano Salvador, que cambia su uniforme militar por la sotana para luego volver finalmente a su identidad militar, representa la simbiosis entre la Iglesia y el Estado. Como soldado fascista está santificado y como diácono está militarizado. Haciendo referencia a la Segunda República, el diácono declara: "Ellos pretendieron alterar el orden de las cosas, modificar los designios del Señor, ignorando que non est potestas nisi a Deo y tuvimos que enseñar un nuevo orden a los inicuos" (107). La expresión Non est potestas nisi a Deo (gobernar es ilegítimo sin Dios) fue reconceptualizada por la Iglesia con el fin de retratar la Segunda República como una aberración ilegal o una divergencia de la trayectoria predestinada de España. Esta visión teleológica afectó en gran medida la forma en que los arquitectos del régimen representaron la historia. Así mismo, sirvió para establecer a los militares y falangistas rebeldes como mártires y para caracterizar los sufrimientos de la guerra como un preludio del martirio. De tal manera, el derramamiento de sangre del rebelde no solo se legitima, sino que también se ve como algo inevitable en el curso de la historia de la redención de la humanidad. Según este punto de vista, cada vez que había una "desorientación" surgía inevitablemente una "cruzada” (sinónimo de "colonización”) para silenciar a la oposición y por consiguiente justificarla en el nombre de Dios.

Este mito religioso del pasado que dio forma a la ideología política y militar del franquismo está a la vez basado en la misoginia. La "Caída" está ligada al pecado de Eva, "la ruina de la humanidad" causada por los deseos de una mujer. Durante el régimen, este dogma religioso nutrió las normas de género patriarcales que exigían el sometimiento de la mujer. En Los girasoles 
ciegos la voz de Salvador sugiere que el régimen no impuso un silencio sobre la sexualidad de las mujeres necesariamente, sino más bien un cierto tipo de discurso basado en una lectura misógina de la Biblia, por lo que la mujer debía asumir una función estrictamente subordinada. Esta interpretación está claramente ilustrada en la confesión de Salvador:

No niego que intuí en Elena el ancestro de Eva, no el de la Eva hermosa, pura y grácil, formada para cautivar el corazón del hombre y subir con él en común vuelo hasta Dios, sino el de la Eva caída, desnuda y arrepentida, la primera inductora del mal. (119)

Aquí, Méndez pone de manifiesto la relación entre los significados atribuidos al cuerpo de la mujer a través de representaciones católicas y las ramificaciones de esos significados en la España de Franco. Salvador manipula la doctrina religiosa para sugerir que el cuerpo femenino es innatamente desviado e inferior, y a la vez oculta el privilegio masculino. Es decir, la superioridad del cuerpo masculino se observa en su posición normativa. El cuerpo femenino se convierte en el objeto de la mirada masculina, deriva en un espectáculo sexual. El autor parece sugerir que esta construcción de género tenía un propósito político más amplio en la posguerra de España; el cuerpo de la mujer republicana, imbuido de significado territorial, se convirtió en el lugar de la venganza. Para el bando nacional el control sobre el cuerpo femenino republicano representó la reafirmación de la superioridad moral e ideológica de los nacionales y la humillación definitiva de los vencidos. Mientras Salvador une la imagen de Eva con la de Elena en una figura moralmente corrupta, la sexualidad se convierte en el territorio de dominio. Para Salvador, la posesión de una mujer republicana se convierte en una metáfora de la supremacía nacionalista.

Hasta este punto he sostenido que Los girasoles ciegos es el vehículo con el que Méndez explora los lazos entre el sometimiento de las mujeres 
republicanas y las ideologías imperialistas y patriarcales. El texto sondea los efectos del poder masculino y cuestiona el rol de la violencia misógina en el mandato nacionalista. ${ }^{12}$ Nos hace trazar una línea entre la lógica franquista y la lógica colonial a través de las confesiones y actitudes de Salvador. Este personaje señala la continuidad: la posesión del cuerpo de la mujer siempre ha sido un robo de poder, un movimiento estratégico en un campo de batalla dominado por los hombres, por lo que el daño psíquico de la mujer violada se ha extendido a su familia y su comunidad. Según la antropóloga Ann Stoler, la sexualidad ilustra la iconografía del dominio (635). Del mismo modo, en Los girasoles ciegos la fantasía de dominación masculina de Salvador implica la cosificación del cuerpo de la mujer republicana. En el siguiente pasaje, Salvador revela su deseo carnal, pero al mismo tiempo afirma de manera contradictoria su supuesta pureza moral innata.

La carne es como los tigres que habitan el hombre, el Anfión que sabe con arte remover todas las piedras, mover todos, todos, los cimientos del alma. La carne, Padre, usted sabrá por el confesionario, es algo prodigioso. Puede inocularnos el orgullo de pecar e incluso la aviesa satisfacción de hacer gozar a un cuerpo que quiere morir y, a pesar de su humillación, exhala un grito de vida capaz de derretir el yunque sobre el que el soldado pretende forjar su acero. (106)

Aquí, la carne simboliza el deseo sexual invariablemente provocado por el cuerpo femenino. El deseo es el tigre (una criatura salvaje) que vive debajo de la piel del hombre, y también es el Anfión, el músico delicado de la mitología griega que construye los muros de Tebas al encantar a las piedras con su lira. Por un lado, la interpretación de la figura femenina (Elena) y el apetito sexual que ésta provoca sugiere la existencia de una profunda ambivalencia en el varón (Salvador). Ella es el agente agresor que debilita las defensas del sexo masculino en un lento proceso de desgaste. 
Por otro lado, Elena es un peón que Salvador utiliza en su búsqueda de poder. Ella es un objeto del deseo que debe ser sometido y penetrado. La metáfora sexual del yunque -un bloque macizo- representa el cuerpo de la mujer, mientras que el acero simboliza el instrumento masculino de dominio. El deterioro del yunque en la fantasía de Salvador presagia la destrucción de Elena. De esta manera, el acero de Salvador se convierte no solo en una herramienta simbólica de la inseminación masculina, sino también en un arma de conquista cultural y política. El género, entonces, se entrelaza íntimamente con la búsqueda del botín imperial. Elena se convierte en un sujeto pasivo cuya existencia femenina depende de los deseos del varón. En el comentario siguiente, Salvador define los atributos "naturales" de la condición de la mujer como el ser delicada, emocional, irracional e infantil, mientras que las características innatas de los hombres incluyen la racionalidad y la fuerza:

El hombre reflexiona con la cabeza para que el pensamiento descienda al corazón donde encuentra su vigor, mientras que la mujer discurre con el corazón para que su instinto recobre la luz de la razón [...] Si al varón corresponden los sonidos brillantes y mayores, a la mujer competen los tonos menores, suaves y velados (127-28).

Con este gesto narrativo Méndez nos señala la forma en que el sistema político nacionalcatólico trató de proteger el sistema de género "natural" de los valores e identidades. Esta perspectiva de género, reivindicada por el régimen, tiene sin embargo sus raíces en una larga historia de discurso patriarcal. La dona Mediterrània; Ilegendes històriques (1916) del positivista catalán Pompeyo Gener (1848-1920) constituye un ejemplo de un texto que intenta confirmar las diferencias psicológicas entre los hombres y las mujeres. Describió a las mujeres, y en particular a las mujeres mediterráneas, como hipersensibles y predestinadas a reaccionar más por impulsos emotivos que por la razón. El argumento de Gener trató de asociar a las mujeres con la 
naturaleza, creando así una dicotomía entre la sensibilidad femenina y la racionalidad masculina (Nash). Como señala Ania Loomba, la división entre la civilización racional masculino-europea por un lado, y el primitivismo femenino e infantil por el otro, es también un tema recurrente en los escritos coloniales (137-38). Esta dicotomía construida se difundió en los libros de texto de la posguerra española, de forma tal que el régimen identificó a España con los conquistadores masculinos y el "nuevo mundo virginal" con las mujeres indígenas "primitivas" (Escudero; Morcillo Gómez). Pilar Primo de Rivera, líder de la Sección Femenina (rama de la Falange dedicada a las mujeres), adoptó este concepto de la distinción biológica entre el varón creativo y la mujer ingenua: "Las mujeres nunca descubren nada; les falta el talento creador, reservado por Dios a las inteligencias masculinas" (cit. en Sueiro y Díaz Nosty 222). Aquí, Primo de Rivera define a las mujeres en su totalidad en términos de carencia. De manera significativa se devalúa su capacidad creativa y su aptitud para el descubrimiento, una posición que alude a los valores imperialistas. Sobre todo, sus comentarios dividen a los hombres de las mujeres por sus diferencias "innatas" y clasifican a las mujeres como un grupo subordinado a los hombres, deficiente en la aptitud física e intelectual. Esta construcción de los roles de género de las mujeres y la distinción biológica da forma a las expectativas que Salvador tiene de Elena en Los girasoles ciegos. Como consecuencia, cuando esta no se ajusta a dichas expectativas, la imagen que tiene Salvador de ella se transforma de madre a puta, la fuente de los pecados de la carne y un territorio por conquistar.

\section{Las tensiones entre la lógica colonialista y anticolonialista}

En Imperial Leather, un libro que analiza las conexiones entre los discursos de género, de raza y de clase que dieron forma al imperialismo británico, Anne McClintock nos recuerda que el mapa era de suma importancia en la lógica imperialista porque sirvió en el saqueo colonial y pretendió captar "la verdad". 
El mapa era una tecnología de la posesión, la cual prometía que los que tenían la capacidad de hacer tales representaciones también tenían el derecho de controlar el territorio (27-28). Los mapas, McClintock observa, también demuestran ciertas ideologías sexistas y racistas: "A medida que los hombres europeos cruzaron el peligroso umbral de sus mundos conocidos, feminizaron las fronteras y los límites de manera ritual. Se plantaron figuras femeninas en los mapas como fetiches en los puntos ambiguos de contacto y en las fronteras y los orificios de la zona perseguida". (24) En Los girasoles ciegos, Salvador recicla esta lógica imperialista para describir el cuerpo de Elena, que simboliza una tierra primitiva y que invita a la conquista. En una confesión, él imagina un mapa que representa un territorio que él llama "Elena". La conquista de ese territorio/cuerpo se convierte en símbolo de la victoria de los nacionales sobre los republicanos y un fetiche que podría ofrecer una sensación de satisfacción o seguridad en ausencia de otras garantías fijas durante la consolidación del Estado franquista.

Fui ingenuo, Padre, porque creí que todas las cosas del mundo tenían ya su nombre, es decir, estaban ya clasificadas [...] Pero hay un campo de nadie, Padre, que no está donde está el pecado y su castigo, ni está tampoco donde la virtud y su recompensa: si tuviera que dibujar un mapa trazaría una ancha franja oscura a la que, con el derecho que se otorga a los descubridores, me atrevería a llamar Elena [...] ¡Santo Tomás se hubiera sorprendido con la complejidad de mi mapa! (115-116)

El cuerpo de la mujer republicana se convierte en un mapa críptico de un territorio sin cultivar, oscuro, mientras que el soldado nacionalista se convierte en el explorador, la luz en la oscuridad espiritual, el "liberador" de la barbarie, el colonizador. La imagen del mapa y su asociación con los animales salvajes tanto excita como perturba al diácono. Su intento de nombrar a la "tierra 
de nadie" Elena es un gesto que indica su deseo de apropiarse del poder del "otro". Se trata de la intención de quitar al otro la libertad de identificarse a sí mismo y, por extensión, de despojarle de su propia subjetividad. A través de este gesto narrativo, el autor pone de relieve la injusticia del acto de cambiar el nombre del "otro" y, por consiguiente, de robarle la autoridad para determinar su propia identidad cultural, sexual y política.

La determinación obsesiva de Salvador para asegurar la propiedad nacionalista y el poder a través de la posesión de Elena se complica por su aparente aspiración de demostrar la moderación de la "civilización" católica en contraposición a la "barbarie" del republicanismo secular. Se trata de proporcionar a Lorenzo una "reeducación ideológica” y el bautismo para que él, y por extensión Elena, pueda alcanzar la expiación moral. Conviene volver al texto Imperial Leather de Anne McClintock, ya que destaca una relación entre el acto imperial de la cartografía y el acto del bautismo cristiano en la medida en que ambos son rituales de creación simbólica y de parto sustituto.

The imperial act of discovery can be compared with the male act of baptism. In both rituals, western men publicly disavow the creative agency of others (the colonized/women) and arrogate to themselves the power of origins. The male ritual of baptism -with its bowls of holy water, its washing, its male midwivesis a surrogate birthing ritual, during which men collectively compensate themselves for their invisible role in the birth of the child and diminish woman's agency. In Christianity, at least, baptism reenacts childbirth as a male ritual. During baptism, moreover, the child is named after the father, not the mother. The mother's labors and creative powers (hidden in her 'confinement' and denied social recognition) are diminished, and women are publicly declared unfit to inaugurate the human soul into the body of Christ. In the eyes of Christianity, women are incomplete birthers: the child must be born again and named, by men. (29) 
[Se puede comparar el acto imperial de descubrimiento con el acto masculino del bautismo. En ambos rituales, los hombres occidentales repudian públicamente la agencia creativa de otros (los colonizados / las mujeres) y se atribuyen a sí mismos el poder de los orígenes. El ritual del bautismo -con sus cuencos de agua bendita, el lavado y sus parteras masculinas- es un ritual de parto sustituto, durante el cual los hombres compensan colectivamente su falta de protagonismo en el nacimiento del niño y disminuyen a la vez la agencia de la mujer. En el cristianismo el bautismo vuelve a representar el parto como un ritual masculino. Durante el bautismo, por otra parte, el niño lleva el nombre del padre y no de la madre. Las labores de la madre y sus poderes creativos (ocultos en su encierro y a los que se les niega reconocimiento social) se encuentran disminuidos, y las mujeres se declaran públicamente no aptas para inaugurar el alma humana en el cuerpo de Cristo. A los ojos del cristianismo, las mujeres son incompletas para parir: el niño tiene que nacer de nuevo y ser nombrado por los hombres.]

Este paralelo entre el ritual católico del bautismo y la cartografía colonial sirve como una lente teórica para interpretar la representación de la Iglesia en Los girasoles ciegos. En el texto, ambos actos se basan en nociones de supremacía masculina. Sirven para reforzar una cultura masculina que usurpa la agencia de las mujeres y limita su papel en la toma de decisiones. Méndez dramatiza esa doble crítica a través de la narrativa de Salvador, en la que Lorenzo constituye un niño no nacido y Elena es una tierra desconocida. Es decir, Lorenzo es una criatura no nacida que espera el bautismo cristiano y el nombramiento simbólico del padre. A la vez, Elena es un lugar desierto a la espera pasiva de la penetración del sexo masculino y la inseminación nacionalista. Mediante el ritual de parto de Salvador, este da vida a una trinidad simbólica: la autoridad cultural de la Iglesia Católica, el privilegio patriarcal de la hegemonía masculina y el orden político del gobierno nacionalista. Esta "matriz de dominación”, para utilizar la expresión de Patricia Hill Collins, sitúa a Salvador como el triunfador de la posguerra española y el núcleo de la familia patriarcal, una 
familia garantizada exclusivamente por la autoridad masculina.

También hay que considerar la narrativa de Lorenzo, uno de los tres narradores de la historia. Reflexiona desde su posición ya de adulto sobre sus propios recuerdos de la infancia. Su narrativa cataloga los efectos a largo plazo de la represión y subvierte la lógica imperialista de Salvador. Al enfatizar un miedo extraño de ser devorado por caníbales, Lorenzo desafía la interpretación del régimen nacionalcatólico como la representación de la "civilización” y los republicanos vencidos como los bárbaros feroces. En el párrafo siguiente, Lorenzo recuerda las historias de horror, basadas tanto en la realidad como en la ficción, que los chicos del vecindario contaban durante los años de la posguerra:

Los protagonistas eran siempre un grupo de niños de nuestra edad acosados por un ejército de leprosos que se movían lenta y amenazadoramente buscando nuestras vísceras como si fueran su única posibilidad de sobrevivir. La lepra no era una enfermedad infecciosa, era una enfermedad del alma y su peligro no estribaba en el contagio sino en su voracidad caníbal. (131)

El temor a ser destripado y devorado por caníbales connota un miedo simbólico de encontrarse en el centro de un ambiente brutal en el que los nacionalistas imponían su poder sobre los republicanos vencidos. La imaginación de Lorenzo también evoca la asociación bíblica de Jesús con los leprosos. Sin embargo, aquí se observa un giro irónico. Salvador se convierte en el leproso o el antisalvador en la imaginación de Lorenzo. La referencia al canibalismo es también una reminiscencia del ritual de la Eucaristía asociado con la Iglesia Católica. Al atribuir el lenguaje caníbal al Estado nacionalcatólico, Méndez invierte la narrativa franquista y demoniza el régimen no secular. En otras palabras, la crueldad, la insaciabilidad y el contagio ejemplificado en el caníbal representan el estado franquista. La imagen del caníbal nacionalista (el colonizador) es una inversión lúcida del discurso imperialista en el cual el colonizador "civilizado" 
temía ser devorado por el "salvaje" colonizado. McClintock argumenta que al igual que en muchas escenas imperiales, el miedo a la inmersión se expresa de manera más aguda en la figura retórica del caníbal (27). En este tema recurrente el miedo a ser engullido por el desconocido se proyecta sobre los pueblos colonizados como su determinación para devorar al intruso entero (27). Esta versión imperialista se manifiesta en las reflexiones paranoicas de Salvador sobre el deseo animal y la ambigüedad del mapa. Sin embargo, su versión se desequilibra por la versión de Lorenzo, que enmarca al colonizador como el cuerpo enfermo y depredador que caza al joven sano e inocente.

La confrontación climática de Salvador con Elena le presenta al diácono un dilema: puede desvelar la brutalidad del programa imperial franquista o mantener la compostura católica "civilizada". El deseo de penetrar y ocupar el cuerpo de Elena pone de relieve la hipocresía inherente a la retórica grandilocuente utilizada para justificar el gobierno franquista. Salvador describe su papel como el de un pastor y su tratamiento de los vencidos como parte de un proyecto benévolo de civilización, cuando en realidad ejerce el poder mediante la intimidación, la manipulación y la violencia. Esto es similar a la actitud que tenían los colonizadores españoles hacia los colonizados en las Américas. Como indica el teórico poscolonial Edward Said, el colonialismo es compatible y tal vez incluso impulsado por formaciones ideológicas que incluyen la noción de que ciertos territorios y poblaciones requieren y suplican la dominación (9). En Los girasoles ciegos, la mujer republicana se convierte desde la perspectiva nacionalista en un objeto deshumanizado, es decir, en un ser reducido a un anexo metafórico del dominio sobre el que los nacionalistas afirmaban su autoridad colonizadora patriarcal.

Paradójicamente, sin embargo, es Salvador quien se encuentra como víctima al borde de la locura. Se puede leer dicha locura no como resultado de un defecto de carácter individual, sino más bien como un síntoma de un contexto social más amplio. En ese contexto, los patrones arraigados en el 
nacionalismo, la militarización y el fundamentalismo religioso producían el potencial de la violencia misógina y la patología. Es decir, tenemos que rastrear las raíces sociales que han generado y han nutrido los actos de discriminación sexista en la España de Franco. Así podemos entender cómo estos actos terminaron oprimiendo no solamente a los enemigos del régimen, sino también a sus seguidores. En el personaje de Salvador, Méndez pone de relieve cómo el sistema de género en España era profundamente patriarcal y al mismo tiempo estaba lleno de contradicciones e inconsistencias.

Por un lado, el soldado nacionalista fue glorificado como símbolo del poder masculino. Este representaba la recuperación del sistema de género y la derrota de la República. Por otro lado, el régimen celebró la figura del sacerdote católico piadoso, refinado y casto como el padre simbólico, el cultivador espiritual y el sustituto en el ritual de parto. En ello yace la ironía de la autoridad nacionalcatólica. Salvador llega a entender que el poder emana no solamente de un arma, sino también del falo. Sin embargo, como diácono se le prohíbe participar en formas sexuales de dominación masculina. Judith Lorber sugiere que las obligaciones morales de la religión por lo general guardan los límites entre los géneros y aseguran que lo que se espera de las personas de cada sexo esté bien conocido y seguido (67). Sin embargo, en el caso del clero las nociones de la masculinidad y sus representaciones de género correspondientes contrastan con las de sus homólogos masculinos no clérigos. Salvador en Los girasoles ciegos es la encarnación de esa tensa relación entre estas masculinidades diferentes en la España de Franco. Como resultado, este experimenta un ataque de angustia, un sentido de fragmentación mental que lo conduce a una retirada de la realidad a la fantasía y la ilusión.

Esta tensión se desata en la escena final. Salvador retira su sotana sacerdotal, que es un gesto simbólico que prefigura su violento intento de violar a Elena. Sin embargo, convenientemente legitima sus acciones como el despliegue de un decreto santo y natural. En su confesión se concibe a sí 
mismo como un hombre religioso y militar que simplemente está tratando de limpiar a un ser caído:

Dios me había utilizado como herramienta de su justicia. Por eso me alineé con los que conquistaron imperios, con los que taparon la boca a los leones, [...] llevando por vigor en el que aún no me reconozco, Padre, arremetí contra el templo bien guardado que esa mujer me tenía vedado. Y bastó un gramo de mi ira para que saliera de su escondite el instigador del mal, el abyecto organizador de ese entramado de mentiras. El marido de Elena estaba oculto en esa casa. (152)

La definición de los vencidos como disidentes de la voluntad de Dios es fundamental en la autodefinición de los nacionalistas como vencedores. También funciona como una herramienta necesaria en la justificación de la violencia erotizada y el saqueo colonial (es decir, la violación de Elena). Al final, Salvador intenta asaltar el territorio republicano físico, psicológico y simbólico: el cuerpo de Elena. En ese momento, Ricardo emerge del armario en un acto de resistencia. Consciente de las consecuencias de su exposición, Ricardo salta de la ventana del apartamento. Desde la perspectiva de Salvador, Dios lo usó como su instrumento de justicia, como un guerrero que extiende el imperio nacionalista y como el guardián de los valores patriarcales según lo definido por el Estado franquista. Es, por lo tanto, paradójico que mientras Salvador pretende proteger los valores familiares cristianos, destruye efectivamente el tejido social de la familia de Elena y Ricardo. La historia termina con la confesión y la exoneración de Salvador. Con este detalle, el autor critica la cosificación de la mujer en las esferas clericales y nacionales bajo el régimen de Franco y sugiere que dicha cosificación ha contribuido a la protección de los perpetradores de la violencia misógina. 


\section{Desenmascarar el secuestro de poder}

Para concluir, Los girasoles ciegos reflexiona sobre las formas en las cuales la Guerra Civil española ha sido glorificada a través de ciertas construcciones de masculinidad agresiva. Méndez nos invita a repensar los actos de sometimiento de las mujeres por el régimen militar y sus múltiples raíces. Traza un enlace entre tales actos y un protocolo patriarcal, la filosofía, la teología y los mitos imperialistas que han representado la dominación de las mujeres como símbolo de la verdadera manifestación de la virilidad. Cuando los actos de violencia como la violación se cuentan desde la perspectiva de tales mitos misóginos, las figuras como Salvador se convierten en los campeones de la virtud moral y religiosa española. Los actos, por ende, consolidan aún más los mitos de la superioridad masculina y la dominación. Se trata de lo que la antropóloga argentina Rita Laura Segato llama en su libro La guerra contra las mujeres (2016) una "pedagogía de crueldad" a través de la cual "la repetición de la escena violenta produce un efecto de normalización de un pasaje de crueldad y, con esto, promueve en la gente los bajos umbrales de empatía indispensables para la empresa predadora" (21). Extrapolando estas ideas, se puede argumentar que estos mitos misóginos reciclados en los medios de comunicación y el sistema educativo no solamente ayudaron a silenciar a las mujeres republicanas, sino que también ayudaron a limitar el poder de todas las mujeres españolas durante la dictadura de Franco. Es decir, incluso aquellas mujeres conservadoras que apoyaban la ideología del régimen militar tenían que sufrir la discriminación sexista en comparación con sus contrapartes masculinos. Un análisis feminista y poscolonial de la novela de Alberto Méndez, en suma, nos hace entender el proceso histórico marcado por las intersecciones del patriarcado, la religión y el Estado militar a través del cual los cuerpos de las mujeres durante el régimen se convirtieron en espacios para la dominación masculina y la violencia. 
Esta investigación de la representación de la historia reciente de España orientada a las relaciones entre la masculinidad, el militarismo y los discursos colonialistas también nos hace reflexionar sobre los paralelos con otras sociedades. Por ejemplo, la ya mencionada antropóloga argentina, Rita Segato, traza una historia de violencia de género en las Américas desde el norte hasta el sur basada en estructuras coloniales. Segato señala las similitudes entre el feminicidio de hoy y los crímenes estatales de las dictaduras militares en el contexto de la guerra fría. Sin colapsar las diferencias históricas, se puede identificar en varios contextos un patrón de suma importancia: la construcción de la identidad masculina dominante está ligada a lo territorial y sostenida por un sistema de comunicación que legitima la usurpación de poder. De acuerdo con Segato, "la cuestión de género es la piedra angular y eje de gravedad del edificio de todos los poderes" y, por lo tanto, de la violencia, ya que la imposición del poder "resulta de una expropiación violenta" (16-19). A través de las estrategias narrativas propias de la literatura, Los girasoles ciegos nos permite reconocer el vínculo entre la violencia, el género y los discursos. Además, nos ayuda a entender por qué dicho vínculo a menudo se ha hecho invisible. Aunque la novela enfatice sobre todo los efectos destructivos de la derrota en vez de las estrategias constructivas de la resistencia, contribuye, en cierta medida, al proceso de derrumbamiento de las bases patriarcales y sus correspondientes mitos misóginos que han autorizado las profundas desigualdades provenientes del secuestro de poder. Visto a través de ese prisma, queda claro que la literatura de la memoria puede constituir una herramienta para desenmascarar las violencias e injusticias del pasado y quizá para construir futuros alternativos. 


\section{Notas}

Otra versión de este ensayo, originalmente en inglés, fue publicada en Anales de la literatura española contemporánea (ALEC) en 2012. Agradezco a los editores de ALEC por haber otorgado los derechos para esta traducción y a los lectores anónimos de ALEC y de Periphērica por sus comentarios. Estos últimos me ayudaron a repensar, profundizar y actualizar mi análisis. Por su lectura de esta traducción y sus recomendaciones, le doy las gracias a María del Carmen Vicente Yepes, correctora de estilo. Todas las traducciones del inglés al español son mías.

1 Muchos lectores recordarán que la constitución republicana de 1931 propició una lucha legislativa para secularizar el Estado español. Los adherentes católicos se vieron amenazados por este movimiento e iniciaron un contramovimiento para proveer a los rebeldes de un marco escatológico que atribuyó significado divino a la rebelión. No todos los insurgentes militares apoyaron una restauración de la hegemonía católica, pero en gran medida unieron sus fuerzas con la Iglesia y su partido político, la CEDA. Véase Nash; Preston. También es importante señalar que hubo sacerdotes que no apoyaron la causa de Franco. Muchos de esos fueron exiliados, encarcelados o ejecutados por el bando nacional. Para más información sobre las divisiones dentro de la Iglesia, véase Brassloff.

2 Véase Gómez, Martín Gaite. Este texto clásico examina cómo los discursos de género fomentaron la vigilancia de la sexualidad de las mujeres, así como la vigilancia del vestido y las normas de comportamiento de las mujeres en la España de la posguerra.

3 Durante la Segunda República, la nueva Constitución extendió el sufragio universal a las mujeres, estableció la libertad de expresión y la libertad de asociación y garantizó el derecho al divorcio. Esta serie de transformaciones sociales en relación con el papel de las mujeres en la sociedad provocó intensas protestas, particularmente entre los grupos católicos conservadores. Después de la guerra, la represión del régimen tenía claramente dimensiones basadas en el género. Las mujeres se vieron afectadas a todo lo ancho del espectro político. Hasta la muerte de Franco en 1975 los anticonceptivos estaban prohibidos, el divorcio era ilegal hasta 1981, el aborto era ilegal hasta 1985 y las oportunidades para que las mujeres realizaran carreras profesionales eran restringidas. Las mujeres casadas tenían que tener la aprobación de su esposo para asegurar el empleo y la propiedad de la tierra, así como para realizar viajes al extranjero.

4 En una ponencia que presenté en la conferencia "Cine-Lit International Conference on Hispanic Film and Fiction" en Portland, Oregón, en febrero de 2011, analicé la versión fílmica de Los girasoles ciegos. Desde mi punto de vista, la adaptación de José Luis Cuerda confunde y limita la crítica de la versión original 
al representar la agresión del protagonista masculino como un deseo sexual. De acuerdo con la antropóloga argentina Rita Laura Segato, la violación "no se trata de agresiones originadas en la pulsión libidinal traducida en deseo de satisfacción sexual, sino que la libido se orienta aquí al poder". (18)

5 Las palabras "republicano" y "republicana” se utilizan aquí como términos generales para las variantes ideológicas del republicanismo. Como sabemos, hubo muchas afiliaciones políticas diferentes en la izquierda política durante la guerra civil. Aquí, utilizo estos términos para referirme a los partidarios de todas las fuerzas progresistas en el lado republicano. Alberto Méndez no diferencia entre activistas políticos, sindicalistas o partidarios generales de la República.

6 También se le atribuye la teoría de la "interseccionalidad" a Patricia Hill Collins. Hill Collins explora específicamente cómo las mujeres negras en los Estados Unidos experimentan la opresión de manera diferente de las mujeres blancas o de los hombres negros.

7 Estas reflexiones fueron inspiradas por el texto Imperial Leather de Anne McClintock que examino a continuación.

8 Imperial Leather de Anne McClintock también examina los discursos y las representaciones coloniales que conectaron la moralidad y la limpieza. El capítulo "Soft-Soaping Empire" examina específicamente los anuncios de jabón que refuerzan los estereotipos coloniales sobre la pureza británica y la superioridad evolutiva.

9 En "Miscegenation, Nation Formation and Cross-racial Identifications in the Early Francoist Folkloric Film Musical”, Jo Labanyi ofrece una crítica lúcida del uso del modelo colonial de mestizaje en los escritos de Giménez Caballero. Mi análisis de Giménez Caballero también se basa en "Women, Asian Hordes and the Threat to the Self in Giménez Caballero's Genio de España” de Jo Labanyi, que examina las intersecciones de la sexualidad, el nacionalismo, y la raza en los textos de Giménez Caballero.

10 Véase el libro Cárcel de mujeres (1939-1945) de Tomasa Cuevas. Cuevas recogió los testimonios de sus compañeras de prisión inmediatamente después de la muerte de Franco. Otras investigaciones importantes que examinan la violencia política del régimen franquista incluyen Los años del terror: la estrategia de dominio y represión del general Franco de Núñez Diaz-Balart; Morir, matar, sobrevivir: La violencia en la dictadura de Franco de Casanova; A Time of Silence: Civil War and the Culture of Repression in Franco's Spain, 1936-1945 de Mike Richards. 
11 Morcillo Gómez examina cómo el discurso educativo franquista construyó la noción de la "verdadera feminidad católica", mientras que Escudero examina cómo se utilizaron los códigos de género en los libros de texto para naturalizar las relaciones de poder entre los hombres y las mujeres, así como entre la España colonizadora y la Latinoamérica colonizada.

\section{Obras citadas}

Abad, Irene. "Las dimensiones de la 'represión sexuada' durante la dictadura franquista." Revista de Historia Jerónimo Zurita, vol. 84, 2009 pp. 65-86.

Balfour, Sebastian. Deadly Embrace: Morocco and the Road to the Spanish Civil War. Oxford UP, 2002.

-. The Reinvention of Spain: Nation and Identity Since Democracy. Oxford University Press, 2007.

-. "The Spanish Empire and Its End: A Comparative View in Nineteenth and Twentieth Century Europe." Imperial Rule. Ed. A.I. Miller and Alfred J. Rieber. Central European UP, 2004.

Brassloff, Audrey. Religion and Politics in Spain: The Spanish Church in Transition, 196296. Macmillan, 1998.

Casanova, Julián. La iglesia de Franco. Madrid: Ediciones Temas de Hoy, 2001.

-. Morir, matar, sobrevivir: La violencia en la dictadura de Franco. Crítica contrastes. Crítica, 2002.

Conrad, Joseph, and Cedric T. Watts. Heart of Darkness and Other Tales. Oxford UP, 1990.

DiGiovanni, Lisa. "Masculinity, Misogyny and Mass in Los girasoles ciegos by Alberto Méndez" Anales de la literatura española contemporánea, vol. 37, no. 1, 2012, pp. 39-61.

Crenshaw, Kimberle. "Mapping the Margins: Intersectionality, Identity Politics, and Violence Against Women of Color," Stanford Law Review, vol. 43, no. 6, 1991, pp. 1241-99.

Cuevas, Tomasa, Mary E. Giles, and Tomasa Cuevas. Prison of Women: Testimonies of War and Resistance in Spain, 1939-1975. State University of New York Press, 1998.

Enders, Victoria Lorée, and Pamela Beth Radcliff. Constructing Spanish Womanhood: Female Identity in Modern Spain. SUNY series in gender and society. State University of New York Press, 1999. 
Escudero, María. "Cortes and Marina": Gender and the Reconquest of America Under the Franco Regime." Constructing Spanish Womanhood: Female Identity in Modern Spain. Ed. Victoria Lorée Enders and Pamela Beth Radcliff. State U of New York Press, 1999, pp. 71-94.

Gener, Pompeyo. La dòna mediterrania; Ilegendes històriques. Societat Catalana Edicions, 1916.

Giménez Caballero, Ernesto. Genio de España; exaltaciones a una resurrección nacional y del mundo. La Gaceta literaria, 1934.

Gómez López-Quiñones Antonio. La guerra persistente: Memoria, violencia y utopía: representaciones contemporáneas de la Guerra Civil española. Editorial Iberoamericana Vervuert, 2013.

—. "El giro irónico de la violencia: La posutopía de la Guerra Civil española en "Los girasoles ciegos y "Capital de la gloria"." Revista canadiense de estudios hispánicos, vol. 34, no. 1, 2009, pp. 99-113.

Graham, Helen. The Spanish Civil War: A Very Short Introduction. Oxford UP, 2005.

Graham, Helen. "Gender and the State: Women in the 1940s." in Helen Graham and Jo Labanyi. Spanish Cultural Studies: An Introduction: the Struggle for Modernity. Oxford UP, 1995, pp. 182-195.

Guerra, Alfonso. "Prólogo.” La Guerra Civil española. Ed. Julián Casanova and Paul Preston. Editorial Pablo Iglesias, 2008.

Herrmann, Gina. "Voices of the Vanquished: Leftist Women and the Spanish Civil War." Journal of Spanish Cultural Studies, vol. 4, no. 3, 2003, pp. 11-29.

Hill Collins, Patricia. Black Feminist Thought: Knowledge, Consciousness, and the Politics of Empowerment. Routledge, 2000.

Intxausti, Aurora. "La cruda mirada de Alberto Méndez sobre la posguerra gana el Nacional de Narrativa," El país, versión electrónica. 7 de octubre de 2005. https:// elpais.com/diario/2005/10/07/cultura/1128636003_850215.html, accedido el 20 de abril de 2018.

Jelin, Elizabeth. State Repression and the Labors of Memory. U of Minnesota Press, 2003.

Kinder, Marsha. Blood Cinema: The Reconstruction of National Identity in Spain. U of California Press, 1993. 
Labanyi, Jo. "Miscegenation, Nation Formation and Cross-racial Identifications in the Early Francoist Folkloric Film Musical." Hybridity and Its Discontents: Politics, Science, Culture. Ed. Avtar Brah and Annie E. Coombes. Routledge, 2000.

-. Myth and History in the Contemporary Spanish Novel. New York: Cambridge UP, 1989.

-. "Women, Asian Hordes and the Threat to the Self in Giménez Caballero's Genio de España.” Bulletin of Hispanic Studies, vol. LXXIII, 1996, pp. 377-87.

Lazzara, Michael J. Prismas de la memoria: narración y trauma en la transición chilena. Cuarto Propio Editorial, 2007.

Loomba, Ania. Colonialism-Postcolonialism. The New Critical Idiom. Routledge, 1998.

López, Guil I y Yeregui C. Albizu. Los girasoles ciegos de Alberto Méndez, diez años después. Boadilla del Monte, Madrid: Antonio Machado Libros, 2015.

Lorber, Judith. "The Social Construction of Gender." Women's Lives: Multicultural Perspectives. Ed. Gwyn Kirk and Margo Okazawa-Rey. McGraw-Hill, 2009.

Martín, Gaite C. Usos amorosos de la postguerra española. Anagrama, 1994.

Mayock, Ellen. "The Poetics of Defeat: Unmasking Masculinities in Alberto Méndez's Los girasoles ciegos." The Dynamics of Masculinity in Contemporary Spanish Culture. Ed. Lorraine Ryan and Ana Corbalán. Taylor and Francis, 2016.

McClintock, Anne. Imperial Leather: Race, Gender, and Sexuality in the Colonial Contest. Routledge, 1995.

Méndez, Alberto. Los girasoles ciegos. Narrativas hispánicas, 354. Anagrama, 2004.

Menéndez y Pelayo, Marcelino. Historia de los heterodoxos españoles. Librería católica de San José, gerente V. Sancho-Tello, 1880.

Morcillo Gómez, Aurora. "Shaping True Catholic Womanhood: Francoist Educational Discourse on Women." Constructing Spanish Womanhood: Female Identity in Modern Spain. Ed. Victoria Lorée Enders and Pamela Beth Radcliff. State U of New York Press, 1999, pp. 51-70.

Nash, Mary. “Mujeres en guerra: repensar la historia.” La guerra civil española. Ed. Julián Casanova and Paul Preston. Editorial Pablo Iglesias, 2008.

-. "Un/contested Identities: Motherhood, Sex Reform and the Modernization of Gender Identity in Early Twentieth-Century Spain." Constructing Spanish Womanhood: Female Identity in Modern Spain. Ed. Victoria Lorée Enders and Pamela Beth Radcliff. State U of New York Press, 1999. 
Núñez Díaz-Balart, Mirta. Los años del terror: la estrategia del dominio y represión del General Franco. La Esfera de los Libros, 2004.

Preston, Paul. The Spanish Civil War: Reaction, Revolution and Revenge. W.W. Norton \& Co., 2006.

—. "Populism and Parasitism: The Falange and the Spanish Establishment, 1939-75." Fascists and Conservatives: The Radical Right and the Establishment in Twentieth Century Europe. Ed. Martin Blinkhorn. Unwin Hyman, 1990, pp. 138-156.

Said, Edward W. Culture and Imperialism. Vintage Books 1994.

Segato, Rita Laura. La guerra contra las mujeres. Traficantes de sueños, 2016.

Stoler, Ann L. "Making Empire Respectable: The Politics of Race and Sexuality Morality in 20th Century Cultures." American Ethnologist, vol. 16, no. 4, Nov. 1989, pp. 63460.

Sueiro, Daniel, and Bernardo Díaz-Nosty. Historia del Franquismo. Ediciones Sedmay, 1978.

Raguer Suñer, Hilario M. La pólvora y el incienso: la Iglesia y la Guerra Civil española, 1936-1939. Ediciones Península, 2001.

- Trans. Hilario M. Raguer Suñer, and Gerald Howson. Gunpowder and Incense: The Catholic Church and the Spanish Civil War. Routledge, 2007.

Richards, Michael. A Time of Silence: Civil War and the Culture of Repression in Franco's Spain, 1936-1945. Cambridge UP, 1998.

Ryan, Lorraine. Memory and Spatiality in Post-Millennial Spanish Narrative. Routledge, 2016.

Vincent, Mary. "The Spanish Civil War as a Religious Conflict." Teaching Representations of the Spanish Civil War. Ed. Noel Valis. MLA, 2007. 